\title{
Intelligent Optical Temperature Sensor based on Polyglycerol Dendrimer Microspheres Encapsulating Hopeites
}

\author{
Mayara Lima Peres de Oliveira ${ }^{a}$ Estácio Tavares Wanderley Neto ${ }^{a}$ (1), \\ Alfredo Antonio Alencar Exposito De Queiroz $z^{b^{*}}$ (1), Alvaro Antonio Alencar de Queiroz $z^{c}$ (1) \\ ${ }^{a}$ Universidade Federal de Itajubá (UNIFEI), Instituto de Sistemas Elétricos e Energia (ISEE), \\ Laboratório de Alta Tensão Prof. Manuel Luis Barreira Martinez (LAT-EFEI), Av. BPS 1303, 37500- \\ 903, Itajubá, MG, Brasil. \\ ${ }^{b}$ Universidade de São Paulo, Instituto de Física de São Carlos (IFSC-USP), Avenida Trabalhador São \\ Carlense, $n^{\circ}$ 400, Parque Arnold Schimidt, 13566-590, São Carlos, SP, Brasil. \\ 'Instituto de Pesquisas Energéticas e Nucleares (IPEN), Centro de Biotecnologia (CEBIO), 05508-000, \\ São Paulo, SP, Brasil.
}

Received: December 12, 2020; Revised: March 24, 2021; Accepted: April 27, 2021

Optical thermometry is a growing technological field which exploits the ability of certain materials to change their optical properties with temperature. In this work, poly(glycerol dendrimer) microspheres (PGLyD) encapsulating cobalt-doped hopeite (CoHo) was synthesized for its potential use as optical thermometer. The structure of the CoHo:PGLyD was studied using scanning electron microscopy (SEM), infrared spectroscopy (ATR-FTIR), X-ray diffraction (XRD) and thermogravimetric analysis (TGA). On the basis of SEM images, the CoHo:PGLyD exhibited a spherical shape in which around $80 \%$ of the microspheres were within $0.82 \mu \mathrm{m}$. A multilayer feed-forward artificial neural network (MLP-ANN) was used to extract the chromaticity profile dependence of the CoHo:PGLyD with temperature. A color change was observed for the CoHo:PGLyD, going from dark blue (490-550 nm) to pale pink $(650 \mathrm{~nm})$ when the temperature changed from $20-200{ }^{\circ} \mathrm{C}$, respectively. These results suggest that CoHo:PGLyD is a promising material for temperature sensing applications.

Keywords: Hopeite microspheres, Optical temperature sensing, Thermochromic sensor.

\section{Introduction}

Optical thermometry (OPT) is a growing technological field that exploits the ability of some materials to change their optical properties with temperature ${ }^{1}$. OPT is a rapidly emerging technique gaining attention for use in noninvasive temperature measurement as remote real-time temperature sensors, taking advantage of its higher optical absorption contrast, fast response, high spatial resolution and sensitivity, and low perturbation of the sample temperature during measurements ${ }^{2}$.

The number of materials for OPT techniques is remarkably large including organic dyes ${ }^{3}$, semiconductors ${ }^{4}$, synthetic diamonds ${ }^{5}$, quantum emitters ${ }^{6}$ and lanthanide complexes ${ }^{7}$. However, the major drawbacks that limit applications of these materials in OPT are the need of ultraviolet/visible/ near-infrared excitations, sophisticated spectrophotometry instrumentation, toxicity and a potentially unstable balance of demand and supply of raw material for the manufacture of OPT devices ${ }^{8,9}$.

Materials that has been shown to be promising for applications in OPT are those which change their color as a reversible and reproducible function of temperature in a phenomena known as thermochromism ${ }^{10}$. A great deal of research endeavors have been devoted to the synthesis of

*e-mail: alvaro.queiroz@ipen.br,dealenquer@gmail.com thermochromic materials and a growing demand for innovative products with temperature-based, color-changing abilities with functional applications in engineering has contributed significantly to this market growth in recent years ${ }^{11}$.

Even though numerous thermochromic materials (TCMs) with different morphologies, preparation and applications have been reported, effective and universal strategies for the development of an ideal material with simple preparation, low cost, excellent performance and practicability are still required ${ }^{12}$.

In the last years, some studies have been reported to demonstrate thermochromic properties of the mineral $\alpha$-hopeite (Ho) doped with $\mathrm{M}^{2+}$ ions $\left(\mathrm{M}^{2+}: \mathrm{Co}^{2+}, \mathrm{Ni}^{2+} \text { and } \mathrm{Mn}^{2+}\right)^{13}$. Ho is a zinc phosphate tetrahydrate $\left[\mathrm{Zn}\left(\mathrm{H}_{2} \mathrm{O}\right)_{4} \mathrm{Zn}_{2}\left(\mathrm{PO}_{4}\right)_{2}\right]$ which $\mathrm{Zn}\left(\mathrm{H}_{2} \mathrm{O}\right)_{4} \mathrm{O}_{2}$ chains in a octahedral molecular geometry and a tetrahedral arrangement of $\mathrm{ZnO}_{4}$ and $\mathrm{PO}_{4}$ chains ${ }^{14}$. The substituent effect of $\mathrm{M}^{2+}$ in the Ho structure appears to play important roles in adjusting their thermochromic behavior such as color and responsive temperature.

The substitution of the zinc at the octahedral site of the $\alpha$-hopeite by cobalt $(\mathrm{Co})$ results in $\left[\mathrm{ZnPO}_{4}\right]$ layers bridged by $\mathrm{Co}\left(\mathrm{H}_{2} \mathrm{O}\right)_{4} \mathrm{O}_{2}$ octahedra originating cobalt-doped hopeite $(\mathrm{CoHo})^{15}$. CoHo is an interesting class of thermochromic temperature indicator which exists in two distinct colored phases. The pink dehydrated form is stable above temperatures 
around $60{ }^{\circ} \mathrm{C}$ while the second, blue hydrated form is stable below that temperature.

CoHo have some difficulties in regard to their applications to OPT. Their water insolubility and the total dehydration of CoHo crystals with heating are problems which limit their practical applications. There are also problems such as suitability for the production of coatings at room temperature $\left(25^{\circ} \mathrm{C}\right)$. Because of these reasons, CoHo particles need to be microencapsulated prior to application in OPT technology. Microencapsulation has many advantages such as the protection of the crystals from the environment preventing the total dehydration of $\mathrm{CoHo}$.

In spite of potentially interesting properties, such as cavities with large surface area, hydrophobic and hydrophilic behavior and electrostatic interactions, to the best of our knowledge, so far no report has introduced any such approach for CoHo microencapsulation by using poly(glycerol) dendrimer microspheres (PGLyD). The PGLyD would allow us to have $\mathrm{CoHo}$ in a more stable way so they could be used in OPT more efficiently. Since PGLyD microcapsules has optical transparency in the portion of the electromagnetic spectrum between $400 \mathrm{~nm}$ and $700 \mathrm{~nm}$, thermal stability up to $300{ }^{\circ} \mathrm{C}$, processing flexibility, and a low elastic modulus in its solid state, this solution allows the best integration in manufacturing processes and the possibility of providing a higher-quality OPT sensor at a reduced cost. Additionally, PGLyD is a kind of glycerol polymer derivative produced from renewable resources.

In this study, CoHo was used as core and PGLyD microspheres were synthesized as the polymeric shell material. The aim was to prepare PGLyD microspheres which change their color reversibly with change temperature. Morphology, particle size distribution, structural characteristics and thermal properties of the CoHo:PGLyD microspheres were determined by scanning electron microscopy (SEM), X-ray diffraction analysis (XRD), Fourier transform infrared spectroscopy (FTIR) and thermogravimetric analysis (TGA), respectively. A screen printing process has been used to fabricate CoHo:PGLyD coatings onto polyethylene terephthalate (PET) films. The dependence of the colorchange behavior of CoHo:PGLyD coatings on temperature was investigated by UV-VIS spectroscopy. An artificial neural network (ANN) was developed to find a quantitative relationship between color change of the CoHo:PGLyD coatings and the temperature.

\section{Experimental}

\subsection{CoHo:PGLyD synthesis}

A polyglycerol dendrimer (PGLyD) with generation 4 was synthesized by repeating the step of allylating a hydroxyl group of glycerol (Sigma-Aldrich) and the step of converting the allyl group into a hydroxyl group by osmium acid oxidation according to previous study ${ }^{16}$.

PGLyD (1.3 mmol), methacrylic acid (1.0 mol, SigmaAldrich) and triphenylphosphine (25 mmol, Sigma-Aldrich) were added together in a $250 \mathrm{~mL}$ jacketed reactor vessel equipped with a magnetic stir bar and reflux condenser. This reaction mixture was heated at $150{ }^{\circ} \mathrm{C}$ for 20 hours at $200 \mathrm{rpm}$ under a stream of nitrogen gas $(25 \mathrm{~mL} / \mathrm{min}$, White
Martins). The resulting methacrylated PGLyD was then precipitated in isopropanol (purity: 99.9\%, Sigma-Aldrich) and dried under reduced pressure at room temperature $\left(25^{\circ} \mathrm{C}\right.$ ) overnight. ${ }^{1} \mathrm{H}-\mathrm{NMR}$ spectra (Bruker ARX $300 \mathrm{MHz}$, DMSO- $\mathrm{d}^{6}$ ) suggested that only one methacrylic group was incorporated into PGLyD structure.

CoHo:PGLyD composite microspheres were synthesized via soap less emulsion polymerization ${ }^{17}$. Initially, the aqueous solution of zinc nitrate $\left(\mathrm{Zn}\left(\mathrm{NO}_{3}\right)_{2} \cdot 6 \mathrm{H}_{2} \mathrm{O}\right.$, Sigma-Aldrich, $0.07 \mathrm{~mol})$ and cobalt(II) nitrate $\left(\mathrm{Co}\left(\mathrm{NO}_{3}\right)_{2}\right.$, Sigma-Aldrich, $0.01 \mathrm{~mol}$ ) were prepared in $10 \mathrm{~mL}$ of distilled and deionized water, separately. The $\mathrm{Zn}\left(\mathrm{NO}_{3}\right)_{2} \cdot 6 \mathrm{H}_{2} \mathrm{O}$ and $\mathrm{Co}\left(\mathrm{NO}_{3}\right)_{2}$ aqueous solution were then added drop wise into the PGLyD $(10 \mathrm{~g})$ over 30 min under constant stirring at room temperature $\left(25^{\circ} \mathrm{C}\right)$. The sodium dihydrogen phosphate solution $\left(\mathrm{NaKH}_{2} \mathrm{PO}_{4}\right.$, Sigma-Aldrich, $0.03 \mathrm{~mol}, 30 \mathrm{~mL}$ ) was then added drop wise into the PGLyD: $\mathrm{Zn}^{2+}: \mathrm{Co}^{2+}$ solution over 1 hour under constant magnetic stirring at room temperature $\left(25^{\circ} \mathrm{C}\right)$. After complete addition of $\mathrm{NaKH}_{2} \mathrm{PO}_{4}$ solution, the $\mathrm{pH}$ of the reaction mixture was adjusted to 3.0 with phosphoric acid $\left(\mathrm{H}_{3} \mathrm{PO}_{4}\right.$, Sigma-Aldrich, $\left.100 \mathrm{mM}\right)$ solution. The aqueous clear solutions turned into visible turbid violet color as the reaction proceeds. Then, soap polymerization of the methacrylated PGLyD carrying the CoHo crystals was carried out in a $250 \mathrm{~mL}$ four-necked flask equipped with thermometer, mechanical stirrer, reflux condenser and nitrogen gas inlet system. Ammonium persulfate (100 mg, Sigma Aldrich) as polymerization initiator for methacrylated PGLyD was added drop wise in the four-necked flask. The mixture was heated at $60{ }^{\circ} \mathrm{C}$ for $1 \mathrm{~h}$ and then at $120^{\circ} \mathrm{C}$ for a further $6 \mathrm{~h}$ under stirring. The CoHo:PGLyD was washed several times with hot $\left(60^{\circ} \mathrm{C}\right)$ deionized water and acetone to remove unreacted reactants, recovered via vacuum filtration and then dried in a vacuum oven at room temperature $\left(25^{\circ} \mathrm{C}\right)$ for $24 \mathrm{~h}$. The yield of the CoHo:PGLyD obtained from such soap less emulsion polymerization was $83 \mathrm{wt} \%$ of a deep violet powder.

\subsection{Characterization and structural study of the CoHo:PGLyD}

The microstructure of CoHo:PGLyD was evaluated by attenuated total reflection infrared spectroscopy (ATRFTIR) using a FTIR Shimadzu IRTracer-100 equipped with a PIKE MIRacle Attenuated Total Reflection (ATR) accessory. The spectra of samples were acquired in the range of wavenumbers from $4000 \mathrm{~cm}^{-1}$ to $600 \mathrm{~cm}^{-1}$.

The morphology of the CoHo:PGLyD was observed under the scanning electron microscopy (SEM). The samples were mounted on an aluminum stub using double-sided tape, covered by a fine gold layer to prevent electric charging and observed on a Carl Zeiss EVO MA 15 electron microscope. Diameters of the CoHo:PGLyD microspheres were measured by using ImageJ software ${ }^{18}$. The mean diameter of each sample was calculated based on the measurements of about 100 randomly selected particles.

Powder X-ray diffraction (XRD) analysis of the CoHo:PGLyD was performed on a Rigaku MiniFlex600 diffractometer with $\mathrm{Cu} \mathrm{K} \alpha$ radiation. The powder patterns were recorded at room temperature in a $2 \theta$ range from 20 to $50^{\circ}$ with an angular step of $0.02^{\circ}$ and a scanning rate of $2^{\circ} / \mathrm{min}$. 
The thermal properties of the CoHo:PGLyD samples were analyzed by thermogravimetric-differential thermal analysis (TG-DTA, Metler TA 4000). The measurements were carried out with $10-15 \mathrm{mg}$ samples in an air environment, from room temperature to $800{ }^{\circ} \mathrm{C}$, and with a heating rate of $5^{\circ} \mathrm{C} / \mathrm{min}$.

\subsection{Fabrication of CoHo:PGLyD sensors}

Thick film of the CoHo:PGLyD thermochromic sensors were fabricated by screen-printing technique employing the paste of CoHo:PGLyD (20 wt\%) with potassium silicate solution $\left(\mathrm{K}_{2} \mathrm{SiO}_{3}\right.$, Diatom, $\left.62 \mathrm{wt} \%\right)$ as a binder and deionized water (16 wt \%) as a solvent. The CoHo:PGLyD paste was symmetrically screen printed on the polyethylene terephthalate films (PET, thickness $100 \mu \mathrm{m}$ ) with a 420 mesh screen mask and dried for $48 \mathrm{~h}$ under vacuum-oven at room temperature $\left(25^{\circ} \mathrm{C}\right)$ to obtain flexible CoHo:PGLyD thermochromic sensors.

\subsection{Optical characterization techniques}

The thermochromic response of the CoHo:PGLyD sensors was measured using diffuse reflection spectroscopy with an integrating sphere attachment to UV-Vis spectrophotometer (Varian Cary 50) over the wavelength range 300-700 nm from $20{ }^{\circ} \mathrm{C}$ to $200{ }^{\circ} \mathrm{C}$. The measurements were performed by placing the samples in front of the incident light window, and concentrating the light reflected from the sample on the detector using a sphere having a barium sulfate-coated interior. The obtained value becomes the reflectance (relative reflectance) with respect to the reflectance of the reference standard white board, which is taken to be $100 \%$.

The color changes of the CoHo:PGLyD sensors with temperature were analyzed with the CIE L*a*b* color space through the use of a portable CIELAB handheld colorimeter (WR10-8 mm, Sucolor). CIE L*a*b* color space describes mathematically all perceivable colors with the dimensions lightness $\left(\mathrm{L}^{*}\right)$, darkest black $\left(\mathrm{L}^{*}=0\right)$ and the brightest $\left(\mathrm{L}^{*}=100\right)$. The red and green opponent colors are represented along the $\mathrm{a}^{*}$ axis while the yellow and blue opponent are represented along the $\mathrm{b}^{*}$ axis. In polar coordinates, $\mathrm{C}^{*}$ represents the chroma or the relative saturation. The parameter $\mathrm{C}^{*}$ ranges from 0 at the center of the circle and represents the completely unsaturated to 100 or more at the edge of the circle for very high chroma ${ }^{19}$.

The recognition of the color changes of the CoHo:PGLyD sensor with temperature was performed from CIE L*a*b* color space coordinates with machine learning algorithm by using a multi-layer perceptron (MLP) architecture based feedforward Artificial Neural Networks (ANN) ${ }^{20}$. The MLP-ANN uses the backpropagation learning algorithm and consists of an input layer, hidden layers and an output layer in the "feedforward" networks configuration where the signal flows from input to output layer. Inputs for the MLP-ANN platform was developed by using the deep learning libraries of TensorFlow (TF) and Keras (K) with Python (version 2.7.12) as the programming language for the CoHo:PGLyD color classification in according to temperature ${ }^{20}$.

The experimental data were randomly divided into two sets: 80 random of data sets were used as training data, 20 data sets were used as testing data and 20 data sets were used for validation. The network architecture was trained using stochastic gradient descent and the categorical cross entropy loss function. The training set was augmented with reverse complement sequences, and gradient descent used a learning rate of 0.1 and momentum parameter of 0.0 . The dataset $\left(y_{i}\right)$ of 60 instances of color patterns of the CoHo:PGLyD at $25^{\circ} \mathrm{C}$ $\left(\mathrm{x}_{1}\right)$ and 60 instances of the CoHo:PGLyD color patterns at $60{ }^{\circ} \mathrm{C}\left(\mathrm{x}_{2}\right)$ classes were used for the ANN classification as $0\left(25^{\circ} \mathrm{C}\right)$ or $1\left(60^{\circ} \mathrm{C}\right)$ through the implementation of the softmax function $\left(\mathrm{S}\left(\mathrm{y}_{\mathrm{i}}\right)\right)$ just before the output layer to predict a probability (p) at each class as an output layer in according to Equation (1):

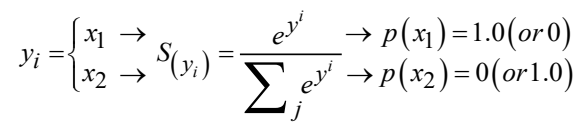

Initially the data set were normalized from $1 \leq\left|L^{*} a^{*} b^{*}\right| \leq 1$. It is important to point out that two neurons at the output layer present the probabilities to be 0 or 1 . A hyperbolic tangent activation function ( $\tanh$ ) in the range $[-1,1]$ was used in the inner layer. The quality of the prediction of the MLP-ANN was characterized through the cross entropy error function $^{21-22}$. Figure 1 illustrates the MLP-ANN implemented in this work.

\section{Results and Discussion}

\subsection{CoHo:PGLyD preparation and characterization}

To prove the presence of CoHo in the PGLyD microspheres, FTIR spectroscopy was used. Figure 2(a) shows the FTIR spectra of the PGLyD and CoHo:PGLyD microspheres. The absorption bands at $3400 \mathrm{~cm}^{-1}, 2900 \mathrm{~cm}^{-1}$ and $1100 \mathrm{~cm}^{-1}$ are associated with the peripheral hydroxyl groups $(\mathrm{OH})$, aliphatic $\mathrm{C}-\mathrm{H}$ and ether (C-O-C) stretching bands of PGLyD microspheres, respectively, which is in good agreement with the literature values ${ }^{23}$. The FTIR spectrum of CoHo:PGLyD microspheres is shown in Figure 2(b). The spectrum reflects

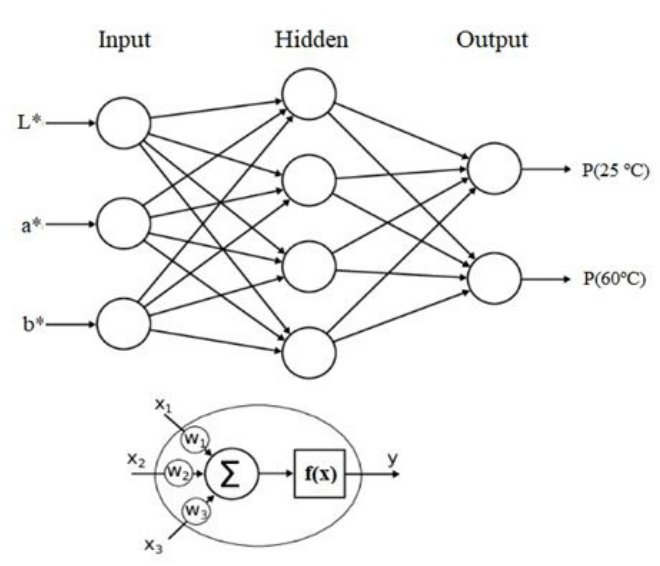

Figure 1. Schematic diagram of the MLP-ANN implemented in this work for study of the color changes of the CoHo:PGLyD with temperature. $\mathrm{L}^{*}, \mathrm{a}^{*}$ and $\mathrm{b}^{*}$ represents the spatial coordinates of the colors and $\mathrm{P}\left(25^{\circ} \mathrm{C}\right)$ and $\mathrm{P}\left(60^{\circ} \mathrm{C}\right)$ represent the probabilities in their respectives temperatures. 


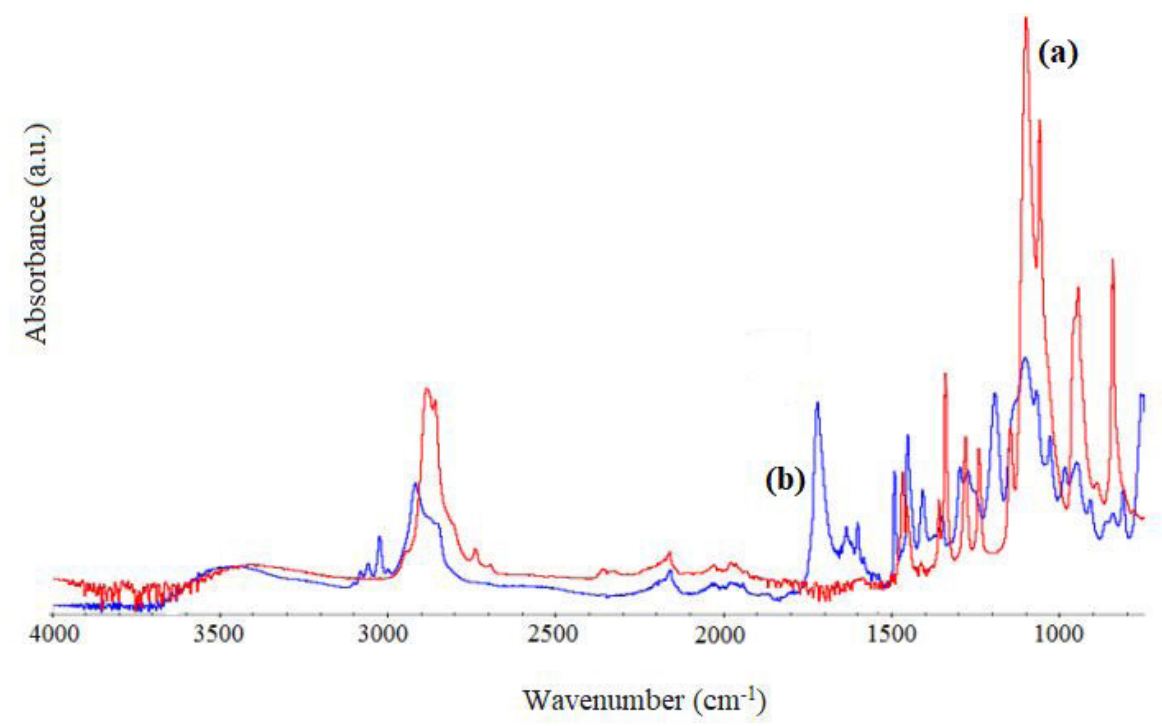

Figure 2. ATR-FTIR spectra of PGLyD (a) and CoHo:PGLyD microspheres (b).
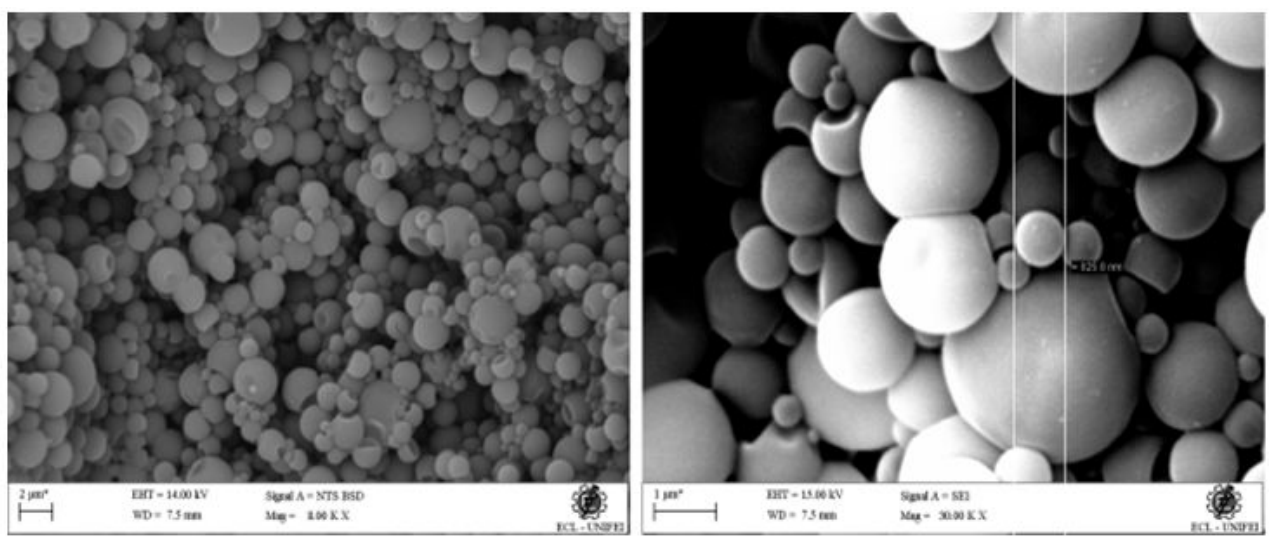

Figure 3. SEM images of CoHo:PGLyD microspheres at magnifications of $8 \mathrm{kX}$ (left) and $30 \mathrm{kX}$ (right), respectively. $\mathrm{k}=1,000$.

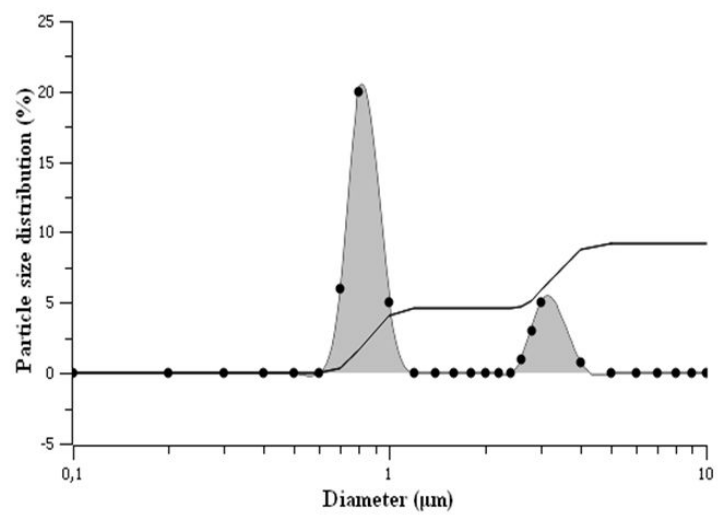

Figure 4. Size distribution analysis of CoHo:PGLyD microspheres after SEM images processing by ImageJ software.

the characteristic absorptions of $\mathrm{CoHo}$ showing characteristic absorptions due to the $\mathrm{PO}_{4}^{3-}$ group from 800 to $1350 \mathrm{~cm}^{-124}$. Water bonding at $1650 \mathrm{~cm}^{-1}$ and $\mathrm{O}-\mathrm{H}$ stretching broad band centered at $3500 \mathrm{~cm}^{-1}$ suggests the presence of water of crystallization $^{24}$. From the above discussion it was confirmed that microencapsulation of CoHo into PGLyD shell had been successfully performed.

Scanning electron microscopy (SEM) images of the CoHo:PGLyD are given in Figure 3. It is evident from these images that the CoHo:PGLyD microspheres are uniformly round with good sphericity and their surface is essentially smooth and was not coalesced together. PGLyD seems to reduce efficiently the surface tension of water avoiding the process of coalescence of the polymeric drops stabilizing the polymer particles especially in the period when the reaction medium becomes very viscous.

The particle size histogram distribution of the CoHo:PGLyD microspheres are shown in Figure 4. According to Fig. 4, particle size distribution of the CoHo:PGLyD microspheres was narrow and unimodal with particle size of about $0.82 \mu \mathrm{m}$. This findings suggested that PGLyD microspheres seems significantly reduce the surface tension of the water so that the dispersed phase may form smaller and more stable droplets favoring the preparation of CoHo:PGLyD microspheres of smaller size diameter ${ }^{25}$. Based on the results, it can be said that CoHo:PGLyD microspheres had uniform and suitable particle sizes for OPT application. 
The XRD patterns of CoHo:PGLyD are shown in Figure 5. XRD patterns of CoHo:PGLyD are almost the same as that of pure CoHo. Nevertheless, the main peaks corresponding to (110) and (200) planes of PGLyD at $2 \theta=21.4^{\circ}$ and $23.8^{\circ}$ can be distinguished. The XRD patterns at the $2 \theta$ interval of $30-80^{\circ}$ agree well with the reported values for $\mathrm{CoH}$ o structure ${ }^{15}$. From the XRD patterns, it can be further ascertained that the crystal structures of $\mathrm{CoHo}$ particles are not significantly altered by the PGLyD. In the polymerization soap less emulsion polymerization process the hopeite precursor's ions are adsorbed on the PGLyD surface droplets to form highly stable metal chelates emulsion ${ }^{26}$. Therefore the final CoHo:PGLyD microspheres could have distinct core-shell morphology where the formed CoHo would act as cores and PGLyD as a shell.

The thermal stability of the CoHo:PGLyD microspheres was determined by the use of thermogravimetric techniques. Figure 6 displays the TGA and their first derivative (dTG) curve representing the temperature of maximum weight loss rate. The TGA/dTG indicates that the mass loss of CoHo:PGLyD may mainly take place in two temperature ranges. In the temperature range of $250{ }^{\circ} \mathrm{C}$ to $500{ }^{\circ} \mathrm{C}$, the mass loss is attributed to the decomposition of the PGLyD organic fraction of CoHo:PGLyD. The weight loss step observed above $500{ }^{\circ} \mathrm{C}$ seems to indicate the loss of water due to the $\mathrm{CoHo}$ dehydration of $\mathrm{CoHo}: \mathrm{PGLyD}^{13}$. TGA measurement could also give indirect information about the amount of CoHo:PGLyD in the organic microspheres. The percentage of the residual weight was around $20 \mathrm{wt} \%$ at $1000{ }^{\circ} \mathrm{C}$ and corresponds to the $\mathrm{CoHo}$ fraction present in PGLyD microspheres. The good thermal stability of the CoHo:PGLyD may contribute to design of thermochromic sensors for engineering applications.

\subsection{Optical properties of the CoHo:PGLyD sensor}

To further investigate the color transition with temperature, the optical properties of the CoHo:PGLyD films at various temperatures were characterized using UV-VIS spectroscopy and the results are shown in Figure 7. The peak at $490 \mathrm{~nm}$ and $550 \mathrm{~nm}$ corresponded to the blue phase of the CoHo:PGLyD at $25{ }^{\circ} \mathrm{C}$ and the peak at $650 \mathrm{~nm}$ was associated with the pink phase at $60^{\circ} \mathrm{C}$ (Fig. 7). The peak intensity at $550 \mathrm{~nm}$ decreased while the intensity of the one at $650 \mathrm{~nm}$ increased with increasing temperature, which was also verified by the color change from blue to pink (Fig. 7) with increasing temperature.

The color change of CoHo:PGLyD appears to be related to the changes in coordination geometry and/or ligand field strength of the $\mathrm{Co}^{2+}$ present in the $\mathrm{CoHo}$ structure. The tetrahedral $\mathrm{Co}^{+2}$ coordination lead to a strong blue color whereas $\mathrm{Co}^{2+}$ in octahedral coordination is known to exhibit a pink color. Since PGLyD is a polyether oxygen-donor ligand able to coordinate in a chelate mode with cobalt the tetrahedral and octahedral structures exist together in equilibrium in CoHo:PGLyD. This equilibrium can be disturbed by changing the temperature basically predicted by Le Chatelier's principle ${ }^{27}$. Thus two metastable longlived complexes are formed in CoHo:PGLyD as result of two competitive reactions. At low temperatures $\mathrm{CoHo}$

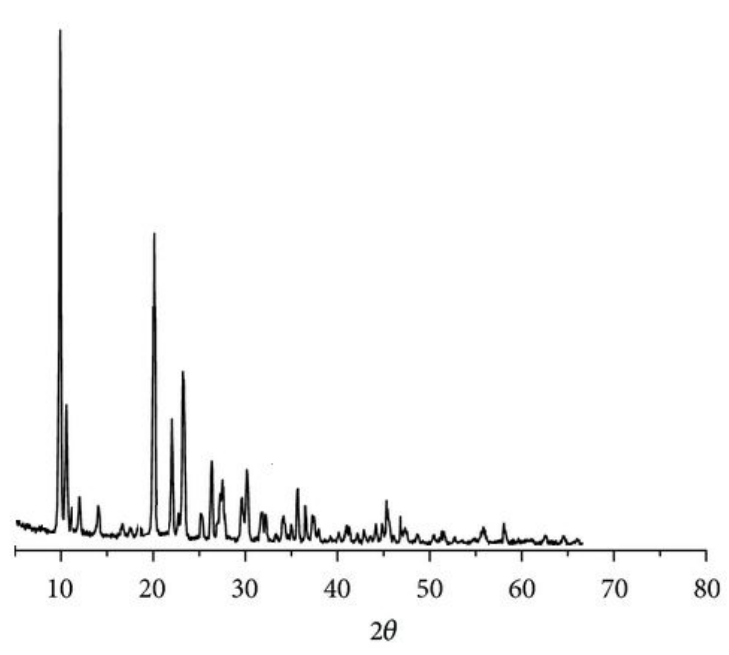

Figure 5. Powder X-ray diffraction of the CoHo:PGLyD microspheres.

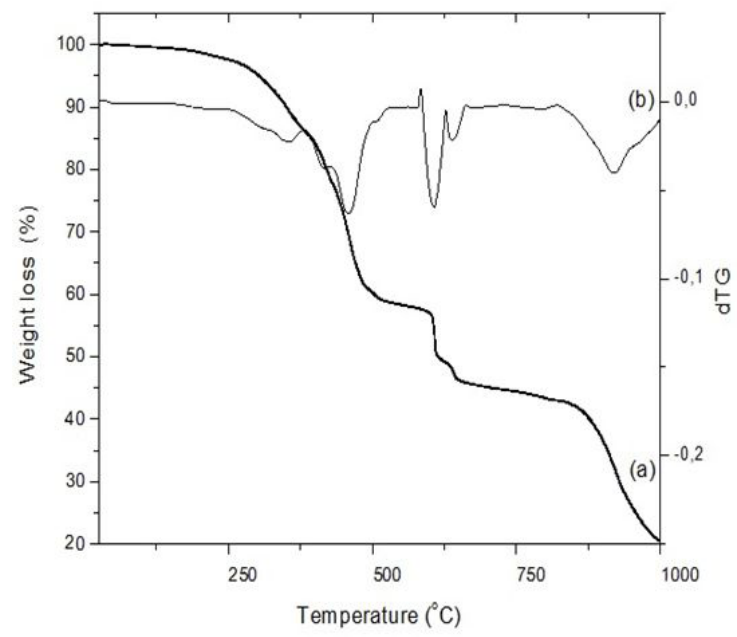

Figure 6. Thermogravimetric analysis (TGA) (a) and their first derivative (dTG) (b) of CoHo:PGLyD microspheres.

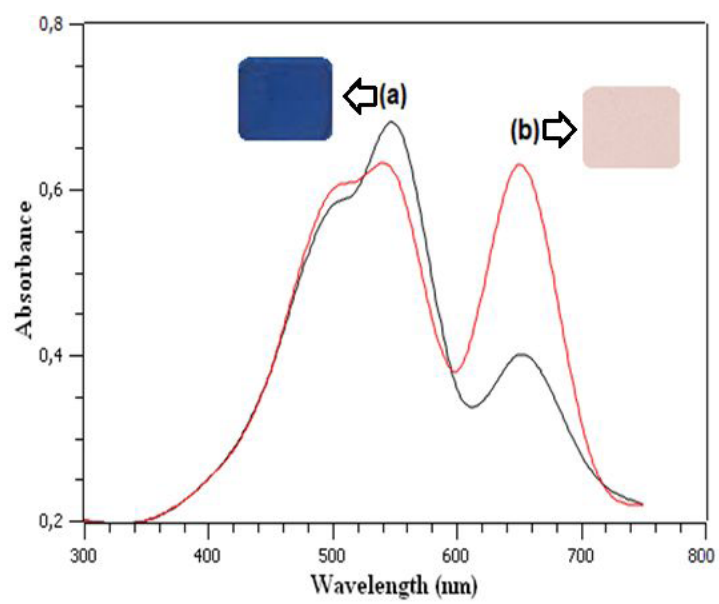

Figure 7. UV-VIS characterization of the thermochromism of the CoHo:PGLyD microspheres coatings at $25^{\circ} \mathrm{C}(\mathrm{a})(-)$ and $60{ }^{\circ} \mathrm{C}$ (b) (一). 
interactions with PGLyD prevail which forms blue colored CoHo:PGLyD microspheres. When at higher temperatures the CoHo hydration water destroy the CoHo:PGLyD complexes and CoHo:PGLyD transforms into its pink state. The microencapsulation of CoHo by PGLyD provides that the equilibrium dark blue/pink to be reversible so that this process can be repeated several thousand times.

CoHo:PGLyD has been shown to have thermochromic properties capable of changing reversibly its optical properties as a function of temperature. The reversibility of the CoHo:PGLyD thermochromism was calculated taking in account Equation (2):

$\mathrm{CI}(\%)=\left[\left(\frac{A_{650}}{A_{650}+A_{550}+A_{460}}\right)_{25}-\left(\frac{A_{650}}{A_{650}+A_{550}+A_{460}}\right)_{60}\right] .100$

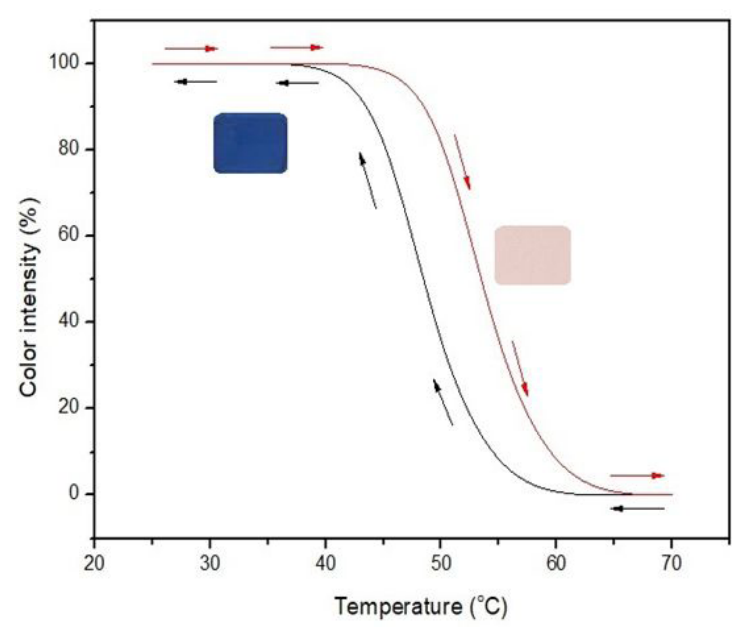

Figure 8. Temperature hysteresis of the CoHo:PGLyD microspheres coatings: heating (-) and cooling (-). Scan rate: $5{ }^{\circ} \mathrm{C} / \mathrm{min}$. where CI is the color intensity (CI) expressed in percentage and $\mathrm{A}$ are the absorbance at respective wavelengths at $25^{\circ} \mathrm{C}$ and $60{ }^{\circ} \mathrm{C}$, respectively.

The color hysteresis were measured applying small temperature gradient on CoHo:PGLyD microspheres with fully relaxed color. This condition ensures the high measurement repeatability required to quantify the dynamic color properties of CoHo:PGLyD. The shape of color hysteresis obtained for CoHo:PGLyD films showed in Figure 8 is characteristic of the single-color reversible thermochromism ${ }^{28}$. The visible color change of CoHo:PGLyD occurs over a temperature range of approximately $5^{\circ} \mathrm{C}$ and the rapid reversibility of the color transition was maintained after several thermal cycles (Fig. 8). Additionally CoHo:PGLyD shows a very small thermal hysteresis, where the temperature at which the color disappears on heating is slightly larger than the temperature at which the color begins to return on cooling (Fig. 8).

\subsection{ANN CoHo:PGLyD automated color recognition}

The color transition associated to the temperature changes was made by the using the CoHo:PGLyD microspheres coating in reflectance mode (Figure 9). The reflected signal from CoHo:PGLyD surface was produced by a red-green-blue (RGB) LED driven by a microcontroller unity (MCU) and detected by a photodiode (PD). The analog signal from PD was then amplified and applied to the MCU where it was converted to digital signals and processed from the RGB space to CIEL*a*b* coordinates through a color conversion algorithm. The corresponding changes in the CIE coordinates of CoHo:PGLyD are shown in Figure 10. With the coordinate $(0.17,0.07)$ at $20^{\circ} \mathrm{C}$, a dark blue color is displayed, and when the temperature increases to $60^{\circ} \mathrm{C}$, the color changes to pink and the CIE coordinate is $(0.32,0.21)$.

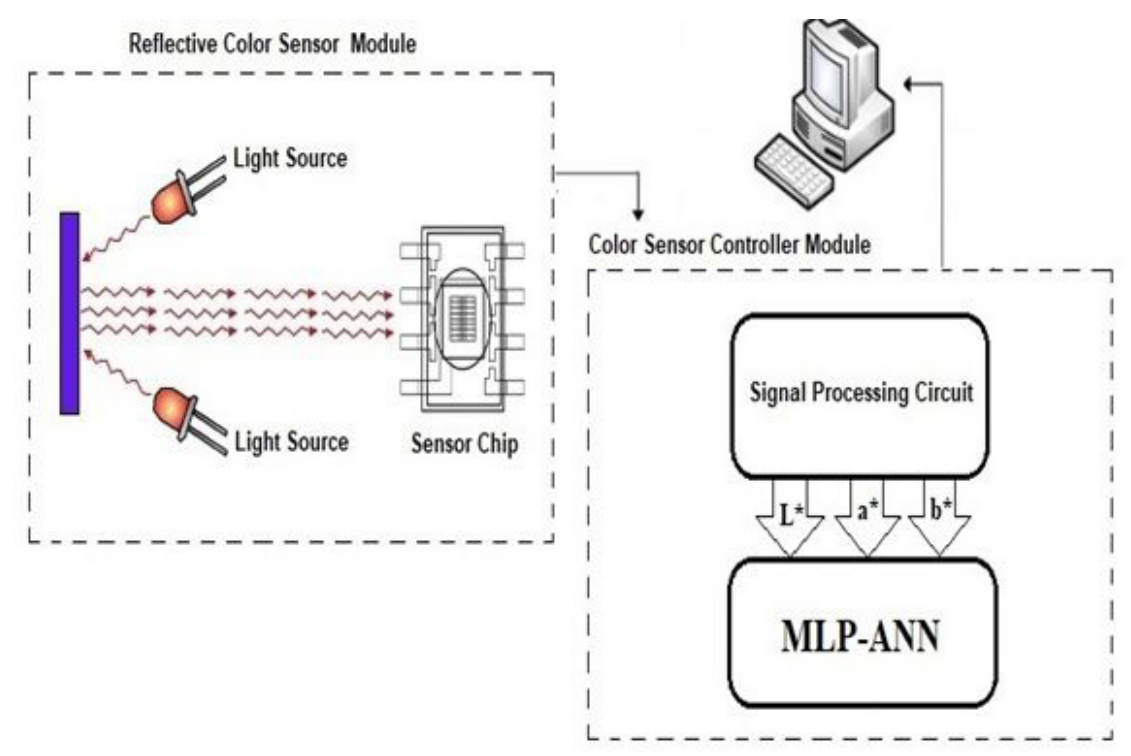

Figure 9. Reflectance mode circuit for monitoring the color transition of CoHo:PGLyD microspheres with temperature. Two D65 LED's were used as light source and simulates the natural daylight. The sensor chip makes use of the TCS230-DB photodiode (PD). The output of the PD was amplified and applied to an 8051 microcontroller. The signal processing circuit converted the RGB values to CIEL*a* $b^{*}$ coordinates for the MLP-ANN processing. 


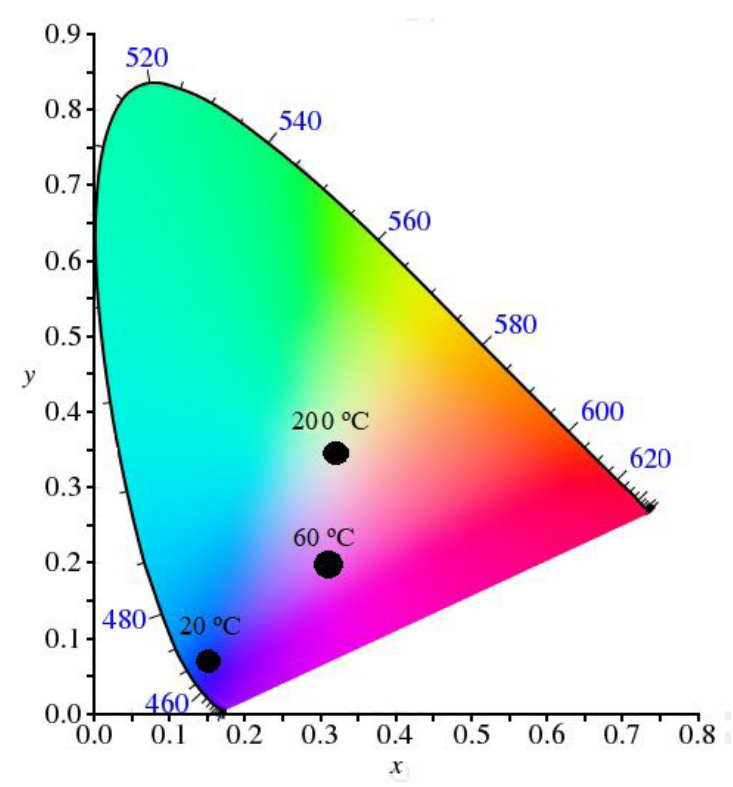

Figure 10. CIE chromaticity diagram showing the color emission of CoHo:PGLyD microspheres at $20^{\circ} \mathrm{C}, 60^{\circ} \mathrm{C}$ and $200^{\circ} \mathrm{C}$, respectively.

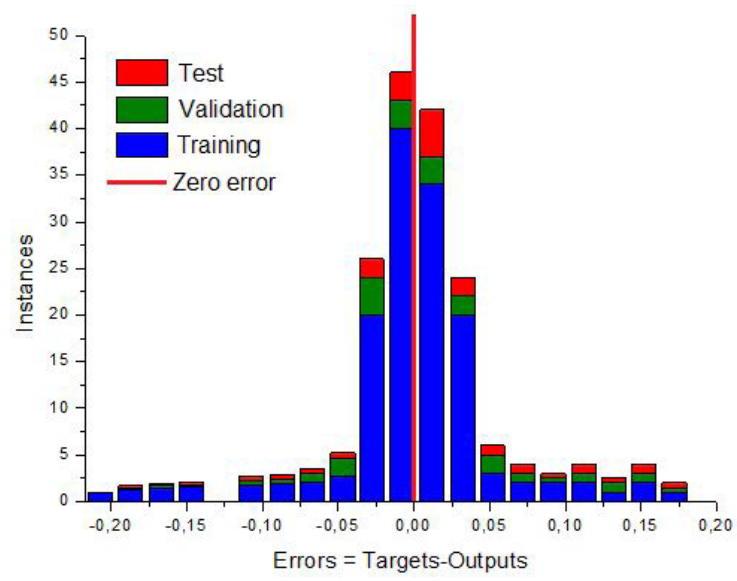

Figure 11. Error histogram of the MLP-ANN with 20 Bins for CIE chromaticity of CoHo:PGLyD microspheres recognition.

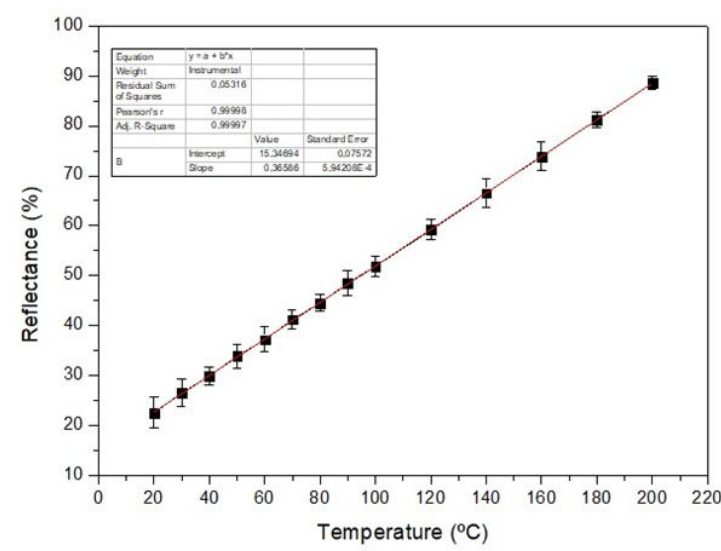

Figure 12. The relationship of reflectance signal (detected at $650 \mathrm{~nm}$ ) of CoHo:PGLyD microspheres with temperature from room temperature $\left(20^{\circ} \mathrm{C}\right)$ to $200{ }^{\circ} \mathrm{C}$.
The error histogram of the trained MLP-ANN for the training, validation and testing steps is presented in Figure 11. Satisfactory results are obtained since the data fitting errors are distributed within a reasonably good range around zero. As shown in Fig. 11 for the chromaticity CIEL*a*b* recognition, all errors are between around $+4.7 \%$. Also, the validation and test errors are between $+6.9 \%$. These results indicate that the MLP-ANN accurately determines the required color in function of temperature with minimum percentage error indicating that CoHo:PGLyD microspheres could be used for real-time analysis of temperature changes. A dozen tests of the MLP-ANN were conducted (results not shown) to verify their repeatability and in this case also, a good performance of the CoHo:PGLyD temperature sensor automated by a MLP-ANN was observed.

The recorded reflectance spectra of the CoHo:PGLyD microspheres measured at $650 \mathrm{~nm}$ as function of temperature is show in Figure 12. It was found that the relationship of the optical signal with temperature from $20^{\circ} \mathrm{C}$ to $200^{\circ} \mathrm{C}$ can be described by an equation of the type $R_{650}=0.37 . T+15.35\left(r^{2}=0.999\right)$ (Fig. 12). In summary, a temperature sensor applicable for monitoring temperature from $20^{\circ} \mathrm{C}$ to $200^{\circ} \mathrm{C}$ can be developed by using CoHo:PGLyD as an optical temperature indicator. Preliminary test results illustrated the potential of application of these sensing CoHo:PGLyD for monitoring temperatures in engineering processes.

\section{Conclusions}

Taking account of the importance of the optical thermometry in technological applications a reversible thermochromic sensor based on CoHo:PGLyD have been studied. FTIR spectroscopy confirmed that microencapsulation of $\mathrm{CoHo}$ into PGLyD shell had been successfully performed. The formation of monophasic CoHo:PGLyD structure was confirmed by XRD analysis data. The SEM micrographs suggest that CoHo:PGLyD are composed of smooth and uncoalesced submicron microspheres with an average size around $0.82 \mu \mathrm{m}$. The TGA-dTG demonstrated that CoHo:PGLyD has adequate thermal characteristics for the development of optical thermometer and visual temperature sensors. The color of CoHo:PGLyD reversibly turned from dark blue to light pink with the color transition temperature of $58{ }^{\circ} \mathrm{C}$, and the thermal stability was over $300{ }^{\circ} \mathrm{C}$. The thermochromic process of CoHo:PGLyD was displayed by reflectance spectroscopy and CIEL*a*b* values in heating-cooling cycle demonstrates their reversible property from dark blue to light pink. A machine learning algorithm was successfully used to recognize and classify the CIE L*a*b* color space coordinates of the CoHo:PGLyD sensor. These results suggests that CoHo:PGLyD sensors could be successfully used for in technological applications for avoid overheating when the environmental temperature exceeds certain operational requirements in the range between $20-200{ }^{\circ} \mathrm{C}$.

\section{Acknowledgements}

Financial support from the Brazilian National Research Council $(\mathrm{CNPq})$ and Higher Education Improvement Coordination (CAPES) are gratefully acknowledged. 


\section{References}

1. Zhao Y, Wang X, Zhang Y, Li Y, Yao X. Optical temperature sensing of up-conversion luminescent materials: fundamentals and progress. J Alloys Compd. 2020;817:1-20. http://dx.doi. org/10.1016/j.jallcom.2019.152691.

2. Coates P, Lowe D. The fundamentals of radiation thermometers. Boca Raton (FL): CRC Press Taylor \& Francis, 2017. Chap. 4, pp. 75-101.

3. Steinegger A, Klimant I, Borisov SM. Purely organic dyes with thermally activated delayed fluorescence- a versatile class of indicators for optical temperature sensing. Adv Opt Mater. 2017;5:1-13. http://dx.doi.org/10.1002/adom.201700372.

4. Kambhampat P, Mack T, Jethi L. Understanding and exploiting the interface of semiconductor nanocrystals for light emissive applications. ACS Photonics. 2017;4(3):412-23. http://dx.doi. org/10.1021/acsphotonics.6b00951.

5. Sildos I, Loot A, Kiisk V, Puust L, Hizhnyakov V, Yelisseyev A, et al. Spectroscopic study of NE8 defect in synthetic diamond for optical thermometry. Diam Relat Mater. 2017;76:27-30. http://dx.doi.org/10.1016/j.diamond.2017.04.002.

6. Chen Y, Tran TN, Duong NMH, Li C, Toth M, Bradac C, et al. Optical thermometry with quantum emitters in hexagonal boron nitride. ACS Appl Mater Interfaces. 2020;12(22):25464-70. http://dx.doi.org/10.1021/acsami.0c05735.

7. Goderski AS, Runowski M, Wozny P, Lavín V, Lis S. Lanthanide upconverted luminescence for simultaneous contactless optical thermometry and manometry-sensing under extreme conditions of pressure and temperature. ACS Appl Mater Interfaces. 2020;12(22):40475-85. http://dx.doi.org/10.1021/ acsami.0c09882.

8. Petriashvili G, Hamdi R, Matranga MA, De Santo MP, Ponjavidze $\mathrm{N}$, Mazzulla A, et al. Thermochromism, a perspective of light to heat conversion mediated by metal nanoparticles. Mol Cryst Liq Cryst (Phila Pa). 2017;649(1):38-44. http://dx.doi.org/10 $.1080 / 15421406.2017 .1303864$.

9. Thermochromic Materials Market Share 2021 Global Future Growth, Size, Regional Trend, Leading Players Updates, Industry Demand, Current and Future Plans by Forecast to 2025 [Internet]. 2021 [cited $2021 \mathrm{Fev} 9$ ]. Available from: https://www. wboc.com/story/43317853/thermochromic-materials-marketshare-2021-global-future-growth-size-regional-trend-leadingplayers-updates-industry-demand-current-and-future-plans.

10. Seeboth A, Lotzsch D. Thermochromic and thermotropic materials. Boca Raton (FL): CRC Press Taylor \& Francis; 2013.

11. Global Thermochromic Materials Market [Internet]. 2020 [cited 2020 Dec 12]. Available from: https://seekarticles.com/ global-thermochromic-materials-market

12. Seeboth A, Lotzsch D. Thermochromic and thermotropic materials. Boca Raton (FL): CRC Press Taylor \& Francis; 2013.

13. Robertson L, Gaudon M, Péchev S, Demourgues A. Structural transformation and thermochromic behavior of $\mathrm{Co}^{2+}$-doped
$\mathrm{Zn}_{3}\left(\mathrm{PO}_{4}\right)_{2} \cdot 4 \mathrm{H}_{2} \mathrm{O}$ hopeites. J Mater Chem. 2012;22(8):3585-90. http://dx.doi.org/10.1039/C2JM14759A.

14. Salek G, Demourgues A, Jubera V, Garcia A, Gaudon M. Mn2+ doped $\mathrm{Zn} 3(\mathrm{PO} 4) 2$ phosphors: irreversible thermochromic materials useful as thermal sensors. Opt Mater. 2015;47:323-7. http://dx.doi.org/10.1016/j. optmat.2015.05.049.

15. Wu WY, Liang XQ, Li YZ. CoZn $2\left(\mathrm{PO}_{4}\right)_{2} \cdot 4 \mathrm{H}_{2} \mathrm{O}$, a cobaltdoped modification of hopeite. Acta Crystallogr Sect E Struct Rep Online. 2005;61(6):105-7. http://dx.doi.org/10.1107/ S1600536805014078.

16. Haag R, Sunder A, Stumbé JF. An approach to glycerol dendrimers and pseudo-dendritic polyglycerols. J Am Chem Soc. 2000;122:2954-5. http://dx.doi.org/10.1021/ja994363e.

17. Ma X, Su X, Zhou B, Zhao X, Tian Y. Synthesis and friction properties of copper/PMMA composites by soapless emulsion polymerization. J Appl Polym Sci. 2011;122(5):2837-42. http:// dx.doi.org/10.1002/app.34339.

18. Schneider CA, Rasband WS, Eliceiri KW. NIH Image to ImageJ: 25 years of image analysis. Nat Methods. 2012;9(7):671-5. http://dx.doi.org/10.1038/nmeth.2089.

19. Klein GA. Industrial color physics. New York: Springer-Verlag; 2010.

20. Abu MA, Indra NH, Rahman AHA, Sapiee NA, Ahma I. A study on image classification based on deep Learning and tensorflow. Int J Eng Res Technol (Ahmedabad). 2019;12(4):563-9.

21. Finnegan A, Song JS. Maximum entropy methods for extracting the learned features of deep neural networks. PLOS Comput Biol. 2017;1-20. https://doi.org/10.1371/journal.pcbi.1005836.

22. Rubinstein TY, Kroese DP. In the cross-entropy method: a unified approach to combinatorial optimization, Monte-Carlo simulation and machine learning. New York: Springer-Verlag; 2004.

23. Zołek-Tryznowska Z, Tryznowski M, Królikowska J. Hyperbranched polyglycerol as an additive for water-based printing ink. J Coat Technol Res. 2015;12:385-92. http://dx.doi. org/10.1007/s11998-014-9643-2.

24. Pawlig O, Trettin R. Synthesis and characterization of $\alpha$-Hopeite, $\mathrm{Zn}_{3}\left(\mathrm{PO}_{4}\right)_{2} \cdot 4 \mathrm{H}_{2} \mathrm{O}$. Mater Res Bull. 1999;34:1959-66. http:// dx.doi.org/10.1016/S0025-5408(99)00206-8.

25. Qiang T, Bu Q, Huang Z, Wang X. Structural and interfacial properties of hyperbranched-linear polymer surfactant. J Surfactants Deterg. 2014;17:959-65. http://dx.doi.org/10.1007/ s11743-014-1592-3.

26. Dzhardimalieva GI, Uflyand IE. Synthetic methodologies and spatial organization of metal chelate dendrimers and star and hyperbranched polymers. Dalton Trans. 2017;46:10139-75. http://dx.doi.org/10.1039/C7DT01916E

27. Blackman AG. Cobalt: inorganic \& coordination chemistry. New York: John Wiley \& Sons; 2011. p. 1-24.

28. Zhu CF, Wu AB. Studies on the synthesis and thermochromic properties of crystal violet lactone and its reversible thermochromic complexes. Thermochim Acta. 2005;425(1):7-12. http://dx.doi. org/10.1016/j.tca.2003.08.001. 